\title{
The behavioural response of anaerobic Rhodobacter sphaeroides to temporal stimuli
}

\author{
Helen L. Packer, David E. Gauden and Judith P. Armitage \\ Author for correspondence: Judy Armitage. Tel: +44 1865 275299. Fax: +44 1865275297. \\ e-mail: armitage@bioch.ox.ac.uk
}

Microbiology Unit, Department of

Biochemistry, University of Oxford, South Parks Road,

Oxford OX1 3QU, UK

\begin{abstract}
The behavioural response of Rhodobacter sphaeroides to temporal changes in the concentration of chemoeffectors, and to stimuli affecting electron transport, was analysed using tethered cells. Populations of photosynthetically grown tethered cells of $R$. sphaeroides showed a transient response, a stop followed by adaptation, to a stepwise reduction in the concentration of chemoattractants (such as organic acids or sugars) and terminal electron acceptors. A step-down response was also measured in free swimming cells to a reduction in light intensity. As this response appears to apply to all effectors this suggests that there is a sensory pathway in anaerobically grown $R$. sphaeroides which responds primarily to a reduction in a stimulus. $R$. sphaeroides therefore responds when moving down a concentration gradient. This is the inverse of the classical Escherichia coli-Salmonella typhimurium model of bacterial sensory behaviour in which bacteria respond primarily when there is an increase in an attractant concentration, i.e. when moving up a gradient. R. sphaeroides does show a chemokinetic response to an increase in concentration of a limited number of compounds but this response is sustained and accompanied by an increase in the rate of flagellar rotation and therefore not simply equivalent to the transient increase in smooth swimming measured in $E$. coli on addition of an attractant.
\end{abstract}

Keywords: Rbodobacter sphaeroides, chemotaxis, aerotaxis, electron transport, phototaxis

\section{INTRODUCTION}

Bacteria are able to sense and respond to a wide range of effectors, including nutrients, light, temperature and $\mathrm{pH}$, and have developed complex signalling systems to detect changes in the presence of these effectors and elicit adaptive motile responses. The sophisticated signalling systems of prokaryotes, as well as being significant molecular pathways in their own right, are also a model for determining the molecular basis of global cellular signalling processes as, in common with all such systems, the signal must be detected, processed (amplified and integrated) and an output produced. The intracellular signalling machinery of the enteric bacteria has been elucidated in some detail (Armitage, 1992; Stock et al., 1989; Taylor et al., 1988). In these organisms a limited range of stimuli is detected through transmembrane methyl-accepting chemotaxis proteins (MCPs) and the signal transduced via CheW to a two-component sensor/ regulator system. This sequence of cytoplasmic phospho- proteins (Che $\mathrm{A}, \mathrm{CheB}, \mathrm{Che} \mathrm{Y}$ ) is involved in processing the sensory signal, transmitting this signal to the flagellar motor and controlling adaptation. However, in some bacterial species transmembrane MCPs have not been identified and different sensory machinery appears to be in operation (Armitage, 1992). One such organism is Rhodobacter sphaeroides.

R. sphaeroides has a single flagellum which either rotates unidirectionally to propel the cell forward or stops rotating, during which time Brownian forces re-orientate the cell (Armitage \& Macnab, 1987). R. sphaeroides is able to respond chemotactically to a wide range of attractants such as amino acids, sugars and organic acids. Until recently MCPs were believed to be absent from $R$. sphaeroides and sensing was thought to be conducted entirely through a metabolism-linked pathway. However, evidence has now been found for the existence of MCP homologues in this species but they may be primarily cytoplasmic rather than transmembrane (Ward et al., 1995b). Downstream of the $m c p A$ homologue a large chemotaxis operon has been identified containing genes homologous to the enteric che $A$, che $\mathrm{R}$, che $W$ and two 
genes encoding homologues of the single enteric che $Y$ (Ward et al., 1995a). In addition to showing a chemotactic response, $R$. sphaeroides shows a second response, chemokinesis, to an increase in the concentration of some compounds such as the organic acids and $\mathrm{K}^{+}$ions. The addition of these compounds results in an increase in the rate of flagellar rotation which is independent of any change in the electrochemical proton gradient (Brown $e t$ al., 1993; Poole et al., 1990). The increase in rotation rate is sustained and may continue for several hours, but a decrease in the stopping frequency which accompanies chemokinesis does adapt, albeit over tens of minutes rather than the seconds to few minutes seen in chemotaxis (Packer \& Armitage, 1994). The role of chemokinesis in cell sensing and motility is unknown but it has now been reported in several other bacterial species.

The chemotactic response is fairly well understood in the enteric bacteria. When Escherichia coli is swimming up a spatial gradient of an attractant, the cell responds by reducing the probability of tumbling, therefore smooth swimming is increased in comparison to behaviour in an isotropic environment (Berg \& Brown, 1972; Berg \& Tedesco, 1975; Block et al., 1983; Dahlquist et al., 1976). When the cell swims down the concentration gradient the probability of tumbling is the same as it is in an isotropic solution. The duration of the sensory response depends upon the size of the stimulus. When small stepwise increases in attractant concentration are delivered to tethered E. coli, the cells rapidly respond by dramatically increasing the counter-clockwise bias of flagellar rotation and then adapt within $4 \mathrm{~s}$ (Segall et al., 1982). When a large stepwise concentration change is made which would saturate the receptors, the cells again show the rapid response but then recover slowly over several minutes. When an attractant is rapidly removed, the cells respond by spinning clockwise but this change in bias is slight when compared to that for the addition of attractant, and the adaptation times are considerably shorter, suggesting that the dominant chemotactic behavioural response in enteric bacteria is to an increase in chemoeffector concentration rather than a decrease.

Although it has long been known that R. sphaeroides shows chemotaxis, the mechanism involved at the level of the flagellar motor has not been investigated. In this study the sensory response of R. sphaeroides was investigated to characterize the behaviour of individual cells when faced with a temporal change in the concentration of a stimulus and to compare this to the E. coli-Salmonella typhimurium model of sensory behaviour.

\section{METHODS}

Growth media and conditions. R. sphaeroides WS8 (wild-type, obtained from W. Sistrom) and WS8N (a spontaneous nalidixicacid-resistant mutant) were grown as previously described with either $5 \mathrm{mM}$ sodium succinate or fructose as the carbon source (Armitage et al., 1985). Cultures were grown either photoheterotrophically, under continuous illumination at $50 \mu \mathrm{mol}$ $\mathrm{m}^{-2} \mathrm{~s}^{-1}$ (Harrison et al., 1994), or anaerobically in the dark with $5 \mathrm{mM}$ fructose as the carbon source and $40 \mathrm{mM}$ DMSO as electron acceptor (Zannoni \& Marrs, 1981). All cultures were grown to late exponential phase.

Analysis of responses of tethered cells in the flow chamber. R. sphaeroides cells $(5 \mu \mathrm{l})$, harvested and resuspended in $10 \mathrm{mM}$ sodium HEPES buffer ( $\mathrm{pH} 7 \cdot 2$ ) with $50 \mu \mathrm{g}$ chloramphenicol $\mathrm{ml}^{-1}$, were incubated on a cover slip in a humidity chamber with an equal volume of $R$. sphaeroides antiflagellar antibody. After $20 \mathrm{~min}$ incubation, the coverslip was loaded onto a flow chamber (Berg \& Block, 1984) and after at least a further $15 \mathrm{~min}$ equilibration in the flow chamber, the cells were observed under phase contrast microscopy at $1000 \times$ magnification. Buffers containing different concentrations of chemoeffectors, oxygen or other electron acceptors were passed through the chamber and the behaviour of tethered cells was analysed. The rotational behaviour of individual tethered cells was measured using the motion analysis system previously described (Poole $e t$ al., 1988). The rotational rate of each cell was recorded every $0.06 \mathrm{~s}$. The probability of each of 10 individual cells being stopped (bias) was calculated for each point in time, the mean stop probability was then calculated for the 10 cells and smoothed over $1.8 \mathrm{~s}$ intervals. This was plotted as stop probability against time. For experiments looking at the effects of chemoeffectors, the merged data came from 10 cells in the same field. Cells grown on DMSO showed reduced motility and these data therefore come from 10 cells from different fields, but from the same sample and treated identically.

Analysis of the response of cells to changes in light intensity. Cells were grown anaerobically under high light intensity $\left(120 \mu \mathrm{mol} \mathrm{m}^{-2} \mathrm{~s}^{-1}\right)$ (Harrison et al., 1994). Growth at this light intensity reduced the quantity of bacteriochlorophyll in the culture by fourfold compared to cells grown at $50 \mu \mathrm{mol} \mathrm{m} \mathrm{m}^{-2} \mathrm{~s}^{-1}$. For free swimming cells, samples taken directly from the growing culture were drawn by capillary action into $0.05 \mathrm{~mm}$ diameter optically flat microslides (Camlabs) after the addition of $50 \mu \mathrm{g}$ chloramphenicol ml $\mathrm{m}^{-1}$. The microslides were sealed at the ends with Vaseline and left in the light (12 V halogen light source, with phase contrast optics) under the microscope for $15 \mathrm{~min}$ before experimentation. The cells were video-recorded for $5 \mathrm{~min}$ at a light intensity of $240 \mu \mathrm{mol} \mathrm{m}^{-2} \mathrm{~s}^{-1}$ and then the light intensity was reduced rapidly, by the addition of neutral density filters, to $13 \mu \mathrm{mol} \mathrm{m} \mathrm{m}^{-2} \mathrm{~s}^{-1}$ and the response recorded. After $5 \mathrm{~min}$ the light level was returned to the original level.

The behaviour of cells was analysed manually from the video recordings as the motion analysis system was unable to detect the cells during the period of light level change. For manual measurement the video was advanced frame by frame and the cell paths plotted and measured.

\section{RESULTS}

\section{Background behaviour of tethered cells}

Wild-type tethered cells of $R$. sphaeroides either spin counter-clockwise, which is equivalent to a run in a free swimming cell, or cease rotation, which is equivalent to a stop in a free swimming cell. The rotational behaviour of 50 photosynthetically grown cells taken from 10 different populations was pooled, analysed and the mean was calculated. The behaviour of populations of cells was measured independently. Cells were tethered in the flow chamber and their rotational behaviour was analysed for 10 min while $\mathrm{N}_{2}$-sparged $10 \mathrm{mM}$ HEPES buffer, $\mathrm{pH} 7 \cdot 2$, was passed through the flow chamber. Tethered cells of $R$. sphaeroides under constant non-stimulated environ- 

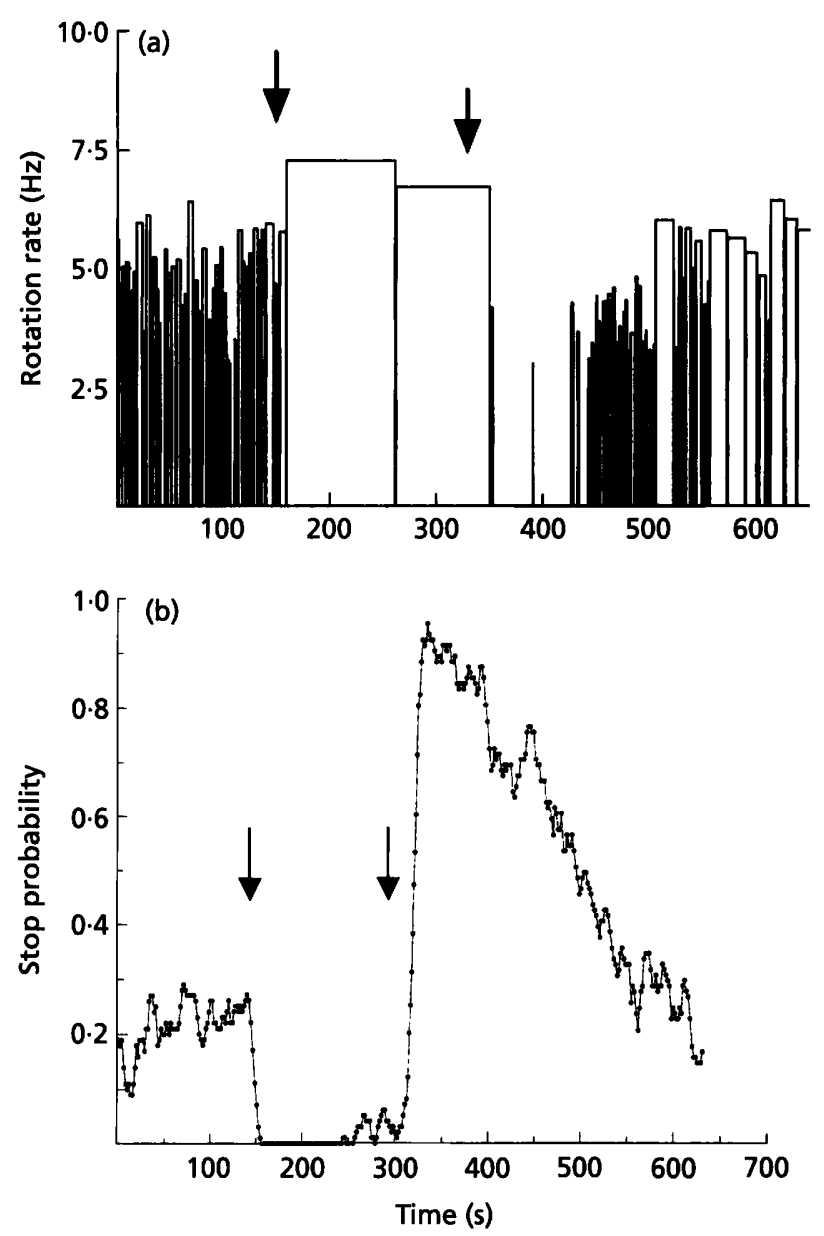

Fig. 1. The response of $R$. sphaeroides to a stepwise increase and decrease in the concentration of the chemoattractant sodium acetate. (a) Response of rotation rate of a single tethered cell to the addition and removal of $1 \mathrm{mM}$ sodium acetate (arrows). The rotation rate increased and the stopping frequency decreased after the step-up in sodium acetate and the removal of acetate resulted in a transient stop followed by adaptation. (b) Stopping probabilities of 10 cells from the same field of view. The addition of $1 \mathrm{mM}$ sodium acetate caused a sustained decrease in stopping frequency of the population and removal resulted in all the cells transiently stopping.

mental conditions had a mean stopping frequency of $0 \cdot 22 \pm 0 \cdot 17$ and thus stopped on average just less than once every $5 \mathrm{~s}$. The behaviour of individual cells was variable with some cells only stopping once during the measurement period of $600 \mathrm{~s}$ (e.g. after a 596.4 s run duration), whereas other cells stopped frequently. The mean stop duration was $1.04 \pm 3.18 \mathrm{~s}(\min =0.06 \mathrm{~s}, \max =102.5 \mathrm{~s})$ and the mean run duration was $2.53 \pm 13.3 \mathrm{~s}$ (min $=$ $0.06 \mathrm{~s}, \max =596.4 \mathrm{~s}$ ). The rotation rates of the cells were also variable with the mean rotation rate at $4.28 \pm 1 \cdot 3 \mu \mathrm{m}$ $\mathrm{s}^{-1}\left(\min =3.5 \mu \mathrm{m} \mathrm{s}^{-1}, \max =11 \mu \mathrm{m} \mathrm{s}^{-1}\right)$. Cells which did not rotate during the experiment were not measured as it was not possible to determine whether the lack of rotation was physiological or an artefact of tethering. In populations of free swimming cells some non-motile cells were, however, usually observed.

\section{Response to changes in concentration of chemoeffectors}

The response of populations of tethered cells to a range of chemoeffectors was investigated. Fig. 1(a) shows the response of a single tethered cell to changes in the concentration of the chemokinetic chemoeffector, sodium acetate. Initially HEPES buffer, $\mathrm{pH} 7 \cdot 2$, alone was passed over the cells. This was then changed for buffer containing $1 \mathrm{mM}$ sodium acetate and then returned to buffer alone. The single cells showed an increase in rotation rate to about $7.5 \mathrm{~Hz}$ and a reduction in stopping frequency. On removal of the sodium acetate the cells stopped for about $50 \mathrm{~s}$ before starting to rotate again and returned to a prestimulus stopping frequency and rotation rate within 3 min. Fig. 1(b) shows the merged data from 10 cells from the same field of view and shows the mean response to the addition and removal of $1 \mathrm{mM}$ sodium acetate. The unstimulated cell populations had a background stop probability of $0 \cdot 22$. When sodium acetate was added the population stop probability was reduced, dropping to 0.05 . Sodium acetate is a chemokinetic effector for $R$. sphaeroides and the response seen on its addition is a chemokinetic response (Packer \& Armitage, 1994). In this experiment the stop probability was reduced for at least $100 \mathrm{~s}$ after which adaptation began. If extrapolated it would take about $10 \mathrm{~min}$ for complete adaptation to occur, a much longer period than would allow integration of this response into chemotaxis. We have previously shown in free swimming cells that this reduction in stopping frequency could be sustained for up to $60 \mathrm{~min}$ (Packer \& Armitage, 1994).

When the acetate was removed from the buffer, all of the cells in the population stopped. The stops were never completely synchronized between cells, suggesting variation in the signalling time from cell to cell, and resulting in a calculated stop probability of 0.95 (Fig. 1b). The response time of the cell population was $64 \mathrm{~s}$. The adaptation time, i.e. the time for all the cells to return to pre-stimulus behaviour, was $196 \mathrm{~s}$. The cells therefore responded to the addition of a chemokinetic effector by a long-term reduction in their stop probability and responded to the rapid removal of the attractant by a transient stop and adaptation over several minutes. A second round of addition and removal of a chemoeffector had the same effect as the initial addition and removal.

The increase in concentration of an attractant which does not cause chemokinesis had no effect on either the stopping behaviour or rotation rate of the cell populations. The response of tethered cells grown with fructose as the carbon source to the stepwise addition and removal of fructose is shown in Fig. 2(a) and (b). Initially the unstimulated cell populations had stop probabilities of 0.19 and 0.35 (Fig. 2a, b). The addition of either $1 \mathrm{mM}$ or $5 \mathrm{mM}$ fructose did not cause any significant change in the behaviour of the cell populations, with mean stop probabilities of 0.15 and 0.35 , respectively. When fructose was removed from the buffer, there was a transient increase in stopping probability. The response to the removal of $1 \mathrm{mM}$ fructose was less sustained than the 


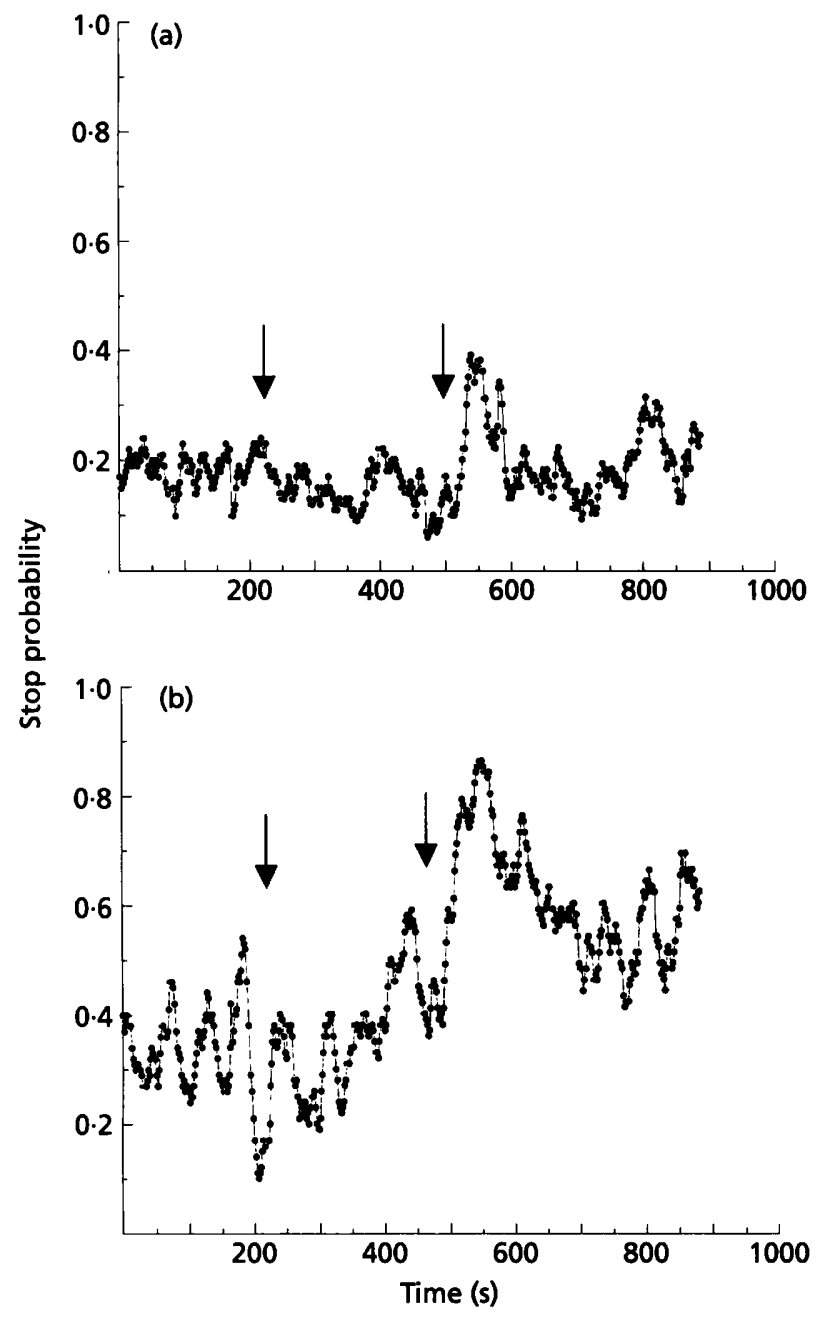

Fig. 2. The response of two populations of 10 cells to the stepwise addition and removal of fructose. The cells were grown using fructose as the sole carbon source. (a) shows no response to $1 \mathrm{mM}$ fructose, added at the first arrow but a transient stop followed by adaptation following removal of the fructose at the second arrow. (b) shows the same experiment as (a) but $5 \mathrm{mM}$ fructose was added at the first arrow. A transient step-down response occurred when the attractant was removed from the buffer. The cells were all from the same field of view in the microscope.

response to the removal of $5 \mathrm{mM}$ fructose. Removal of $1 \mathrm{mM}$ fructose resulted in a response time of $41 \mathrm{~s}$; the stop probability rose to 0.4 and adapted over $29 \mathrm{~s}$. The response time to the removal of $5 \mathrm{mM}$ fructose was $76 \mathrm{~s}$; the mean stop probability increased to 0.88 with an adaptation time of $71 \mathrm{~s}$. The cells therefore only showed a behavioural response to the removal of fructose and did not respond to its addition.

To determine whether the step-down response was a common response to all chemoeffectors in photosynthetically grown $R$. sphaeroides, a range of chemoeffectors was investigated. The non-chemokinetic chemotactic effectors fructose and glucose only caused a behavioural response when the concentration was de-

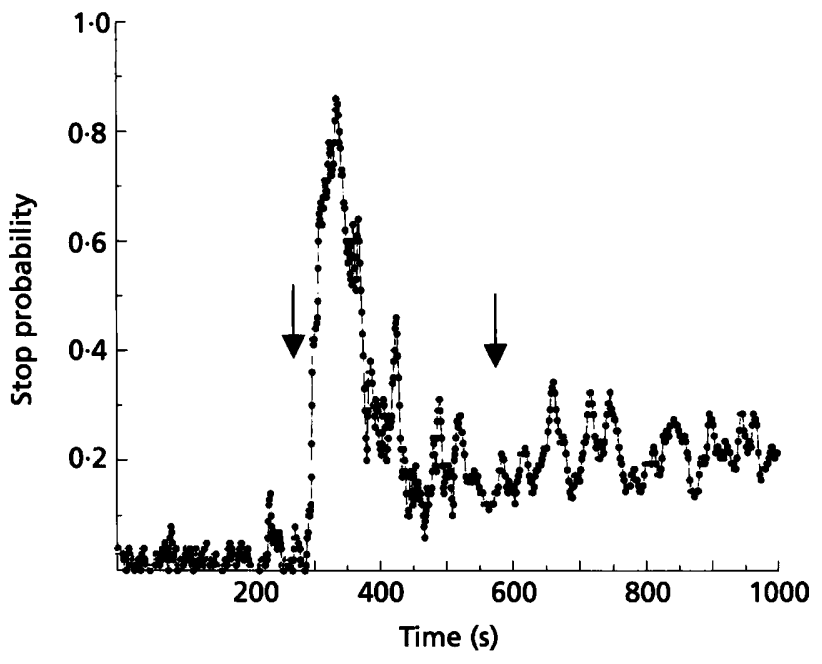

Fig. 3. The response of a population of 10 anaerobically grown tethered cells to a change in oxygen concentration. Initially the cells were in $\mathrm{N}_{2}$-sparged HEPES buffer, $\mathrm{pH} \mathrm{7.2}$; this was changed at the arrow to air-saturated buffer and changed back to $\mathrm{N}_{2}-$ saturated buffer at the second arrow. A transient step-down response occurred when the concentration of oxygen was increased. The cells were from the same population.

creased, not when it was increased. The chemokinetic chemoeffectors succinate, pyruvate, propionate, lactate and malate all produced the same response as acetate with a sustained decrease in stopping frequency on their addition but a transient step-down response on their removal.

\section{Response to changes in light intensity}

The response of populations of free swimming cells of $R$. sphaeroides to a step-down in light intensity was analysed. Initially the population was swimming at $29.3 \pm 6.8 \mu \mathrm{m}$ $\mathrm{s}^{-1}$. When the light level was decreased from 240 to $13 \mu \mathrm{mol} \mathrm{m} \mathrm{m}^{-2} \mathrm{~s}^{-1}$, the whole cell population stopped swimming for $2 \cdot 8 \pm 0 \cdot 65 \mathrm{~s}$ and then resumed swimming at a lower swimming speed of $14.5 \pm 6.2 \mu \mathrm{m} \mathrm{s}^{-1}$. When the light level was returned to the original level, the cell populations did not show any change in stopping frequency but simply increased their swimming speed back to pre-stimulus levels.

\section{Response to changes in concentration of an electron acceptor}

The effect of a change in $\mathrm{O}_{2}$ concentration on photoheterotrophically grown cells was investigated. Tethered cells were incubated under normal light intensity in the flow chamber with $\mathrm{N}_{2}$-saturated HEPES buffer containing $1 \mathrm{mM}$ succinate. The background mean stop probability was 0.02 (Fig. 3). When the oxygen concentration in the buffer was increased by switching to airsaturated buffer, the cells responded transiently by stopping (stop probability of $0 \cdot 87$ ). The response time of the cell population was $39 \mathrm{~s}$ and the adaptation time was 


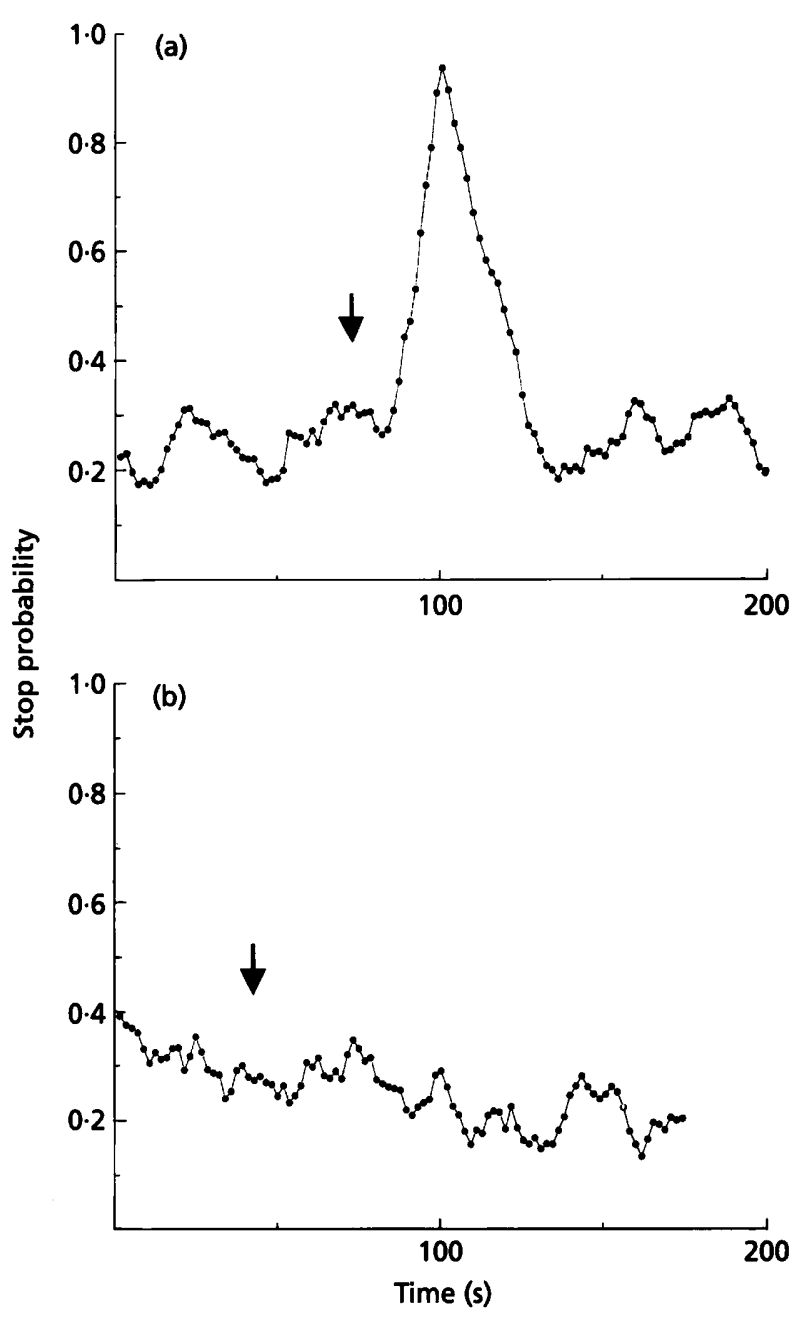

Fig. 4. The response of a population of 10 cells grown anaerobically in the dark to a stepwise change in the concentration of the terminal electron acceptor DMSO is shown. The experiment was conducted under low illumination. Initially the cells were in $\mathrm{N}_{2}$-saturated HEPES buffer, $\mathrm{pH} 7 \cdot 2$, containing $20 \mathrm{mM}$ DMSO. (a) DMSO was removed at the arrow. (b) DMSO was replaced at the arrow. A transient response occurred on the removal of DMSO. The same cells were subjected to the step-up and step-down in DMSO, but because of the reduced swimming seen in DMSO grown populations, the cells were from several fields and the data merged.

$68 \mathrm{~s}$. The stop probability of the cell population did not completely return to the pre-stimulus level of 0.02 but remained at $0 \cdot 2$. When aerobic buffer was changed back to anaerobic buffer, the cell population did not respond and the mean stop probability remained at $0 \cdot 23$.

Cells grown anaerobically in the dark with DMSO as a terminal electron acceptor were tethered and incubated in a buffer containing $20 \mathrm{mM}$ DMSO and $2 \mathrm{mM}$ fructose, and the rotational rate of the cells was measured under low light $\left(34 \mu \mathrm{mol} \mathrm{m} \mathrm{m}^{-2} \mathrm{~s}^{-1}\right)$. The cell population had a mean stop probability of $0 \cdot 24$ (Fig. 4 ). When the buffer was changed to DMSO-free buffer, the cells briefly stopped rotating and the stop probability increased to 0.94 (Fig. 4a). The response time was brief, $23 \mathrm{~s}$, and the adaptation time was $30 \mathrm{~s}$. There was no response when the concentration of DMSO was increased back to $20 \mathrm{mM}$ and the mean stop probability after the change was $0 \cdot 2$ (Fig. 4b).

\section{DISCUSSION}

R. sphaeroides has previously been shown to respond chemotactically to a wide range of chemoeffectors, all of which are metabolites, with the accumulative response dependent upon at least partial metabolism (Poole et al., 1993). Analysis of the behaviour of individual cells of anaerobic, photosynthetically grown $R$. sphaeroides to changes in the concentration of chemoeffectors has identified adaptive responses. Tethered cells responded to a step-down in the concentration of a chemoeffector, such as an organic acid or sugar, by stopping flagellar rotation and then returning to pre-stimulus behaviour over a few minutes. We have previously shown that the presence of arsenate inhibits the chemotactic response in $R$. spbaeroides and analysis of tethered cells in the presence of arsenate showed that the transient stop to a step-down in chemoeffector concentration was no longer present, indicating that the transient increase in stopping is part of the chemosensory system (Packer \& Armitage, 1994) and suggesting that periodic stopping of motor rotation in $R$. sphaeroides is the equivalent of tumbling in enteric bacteria. However, in addition to this, a stepwise increase in the concentration of a compound which was both a chemoattractant and a chemokinetic effector produced a longterm but adaptive decrease in the stop probability.

It appears, therefore, that the motile behaviour of $R$. sphaeroides is as follows: (i) unstimulated swimming is punctuated by stops for random direction changing; (ii) when an increase in the concentration of a non-chemokinetic metabolite is sensed, e.g. when a cell moves up a gradient, there is no change in behaviour and the cell continues swimming normally; (iii) if there is a decrease in concentration of the metabolite, e.g. when a cell swims down a gradient, the cell stops transiently. Mathematical modelling of this pattern (L. Kruglyak, personal communication) using simulation based on that used for $E$. coli (Schnitzer et al., 1990) predicted accumulation of cells at regions of high effector concentration. The behaviour of a population of chemokinetically stimulated cells was also mathematically simulated and led to an accumulation of cells only if direction-dependent changes in stopping frequency (i.e. chemotaxis) also occurred; however, this model gave weaker accumulation than a solely chemotactic effector. The decrease in stop probability on the addition of a chemokinetic effector is not the same as the response of $E$. coli to attractant as, in $R$. sphaeroides, this response is large, sustained over tens of minutes and accompanied by an increase in rate of rotation of the flagellar motor. However, as the change of stop probability does slowly adapt this may add to a chemotactic response.

Photoheterotrophically grown cells responded to oxygen by transiently stopping. Parallel experiments to measure the membrane potential of cells under similar conditions 
revealed that this dropped slightly upon addition of oxygen if the cells were incubated in low light but not if they were in high light (D. E. Gauden \& J. P. Armitage, unpublished data). This suggests that in high light, where photosynthetic electron transport is very rapid, there is no significant effect on electron flow when oxygen is present. But at low light, when photosynthetic electron transport will be operating at a reduced rate, electron transport to $\mathrm{O}_{2}$ causes a transient reduction in photosynthetic electron transport. Anaerobically DMSO-grown R. sphaeroides showed chemotaxis to DMSO. Tethered DMSO-grown cells showed an increase in stopping to a step-down removal of DMSO, conditions under which there is a fall in the rate of electron transport (Gauden \& Armitage, 1995). Similarly, in photoheterotrophically grown cells, a drop in light intensity results in a decrease in the rate of cyclic electron transport and also a step-down response followed by adaptation. A return to high light did not cause any change in stopping pattern even though electron transport rates increased, although swimming speed did increase, presumably because the electrochemical proton gradient increased. R. sphaeroides may therefore sense the rate of electron transport and adapt to a particular rate; a decrease in the rate, even briefly, causing a transient increase in stopping frequency. Whether the primary signal is a change in the size of the electrochemical proton gradient or the redox state of one of the electron transport components is unresolved but recent data suggest it may be a redox sensing mechanism (Gauden \& Armitage, 1995).

None of the non-chemokinetic chemoeffectors caused a transient response to an increase in the concentration of an effector. It is, however, possible that there are very short stops or pauses in flagellar rotation in addition to the long stops. Any change in the number of short stops might be missed when the behaviour of tethered cells is followed, as the increased viscous drag on the cell body and the compliance of the hook might mask these and the tracking system cannot detect stops shorter than $60 \mathrm{~ms}$. Alternatively, as the transient stop and adaptation to a decrease in the concentration of effector is the only response which seems to occur for all effectors, photosynthetically grown $R$. sphaeroides may have a chemotactic pathway which only responds to a decrease in stimulus. The longer term reduction in stop probability on the addition of chemokinetic effectors may be under the control of a different chemosensory pathway. The identification of a second che $Y$ homologue in $R$. sphaeroides suggests that, unlike $E$. coli, there are at least two sensory pathways controlling the flagellar motor. Preliminary examination of the behaviour of aerobically grown cells indicates that they show a different pattern of behaviour to anaerobically grown cells, suggesting that chemosensing in general in R. sphaeroides is much more complex than that shown by $E$. coli and is influenced by the physiological state of the cell.

This study shows that the behavioural mechanism in photosynthetically grown $R$. sphaeroides appears to be the opposite of the 'optimistic' response of enteric species where cells only respond to an increase in attractant concentration. Photosynthetic R. sphaeroides responds 'pessimistically' only showing a response if the attractant concentration decreases.

\section{ACKNOWLEDGEMENTS}

The authors would like to thank the Wellcome Trust and the B BSR C for their generous support of this work.

\section{REFERENCES}

Armitage, J. P. (1992). Behavioural responses in bacteria. Annu Rev Pbysiol 54, 683-714.

Armitage, J. P. \& Macnab, R. M. (1987). Unidirectional intermittent rotation of the flagellum of Rbodobacter sphaeroides. J Bacteriol 169, 514-518.

Armitage, J. P., Ingham, C. \& Evans, M. C. W. (1985). Role of the proton motive force in phototactic and aerotactic responses of Rhodopseudomonas sphaeroides. J Bacteriol 163, 967-972.

Berg, H. C. \& Block, S. M. (1984). A miniature flow cell designed for rapid exchange of media under high-powered objectives. $J$ Gen Microbiol 130, 2915-2920.

Berg, H. C. \& Brown, D. A. (1972). Chemotaxis in Escherichia coli analysed by three-dimensional tracking. Nature 239, 500-504. [reprinted with addendum in Antibiot Chemother (1974) 19, 55-78].

Berg, H. C. \& Tedesco, P. M. (1975). Transient response to chemotactic stimuli in Escherichia coli. Proc Natl Acad Sci USA 72, 3235-3239.

Block, S. M., Segall, J. E. \& Berg, H. C. (1983). Adaptation kinetics in bacterial chemotaxis. $J$ Bacteriol 154, 312-323.

Brown, S., Poole, P. S., Jeziorska, W. \& Armitage, J. P. (1993). Chemokinesis in Rhodobacter sphaeroides is the result of a long term increase in the rate of flagellar rotation. Biocbim Biophys Acta 1141, 309-312.

Dahlquist, F. W., Elwell, R. A. \& Lovely, P. S. (1976). Studies of bacterial chemotaxis in defined concentration gradients. A model for chemotaxis toward L-serine. J Supramol Struct 4, 329(289)342(302).

Gauden, D. E. \& Armitage, J. P. (1995). Electron transport dependent taxis in Rhodobacter sphaeroides. J Bacteriol 177, 5853-5859.

Harrison, D. M., Packer, H. L. \& Armitage, J. P. (1994). Swimming speed and chemokinetic response of $\mathrm{R}$ hodobacter sphaeroides investigated by natural manipulation of the membrane potential. FEBS Letts 348, 37-40.

Packer, H. L. \& Armitage, J.P. (1994). The chemokinetic and chemotactic behaviour of Rhodobacter sphaeroides: two independent responses. J Bacteriol 176, 206-212.

Poole, P. S., Sinclair, D. R. \& Armitage, J. P. (1988). Real time computer tracking of free-swimming and tethered rotating cells. Anal Biochem 175, 52-58.

Poole, P. S., Brown, S. \& Armitage, J. P. (1990). Swimming changes and chemotactic responses in Rhodobacter sphaeroides do not involve changes in the steady state membrane potential or respiratory electron transport. Arch Microbiol 153, 614-618.

Poole, P. S., Smith, M. J. \& Armitage, J. P. (1993). Chemotactic signalling in Rhodobacter sphaeroides requires metabolism of attractants. J Bacteriol 175, 291-294.

Schnitzer, M. J., Block, S. M., Berg, H. C. \& Purcell, E. M. (1990). Strategies for chemotaxis. In Biology of the Chemotactic Response, pp. 15-34. Edited by J. P. Armitage \& J. M. Lackie. Cambridge: Cambridge University Press. 
Segall, J. E., Manson, M. D. \& Berg, H. C. (1982). Signal processing times in bacterial chemotaxis. Nature 296, 855-857.

Stock, J. B., Ninfa, A. J. \& Stock, A. M. (1989). Protein phosphorylation and regulation of adaptive responses in bacteria. Microbiol Rev 53, 450-490.

Taylor, B. L., Johnson, M. S. \& Smith, J. M. (1988). Signalling pathways in bacterial chemotaxis. Bot Acta 101, 101-104.

Ward, M. J., Bell, A. W., Hamblin, P. A., Packer, H. L. \& Armitage, J. P. (1995a). Identification of a chemotaxis operon with two che $Y$ genes in Rhodobacter sphaeroides. Mol Microbiol 17, 357-366.
Ward, M. J., Harrison, D. A., Ebner, M. \& Armitage, J. P. (1995b). Identification of a methyl-accepting chemotaxis protein in Rhodobacter sphaeroides. Mol Microbiol 18, 115-121.

Zannoni, D. \& Marrs, D. L. (1981). Redox chain and energy transduction in chromatophores from Rbodopseudomonas capsulata cells grown anaerobically in the dark on glucose and dimethylsulphoxide. Biochim Biophys Acta 637, 96-106.

Received 7 August 1995; revised 12 October 1995; accepted 23 October 1995. 